\title{
The prevalence of paediatric skin conditions at a dermatology clinic in KwaZulu-Natal Province over a 3-month period
}

\author{
O S Katibi, ${ }^{1,2}$ MBBS, FMCPaed, MMedSci; N C Dlova, ${ }^{2}$ MB ChB, FCDerm, PhD; \\ A V Chateau, ${ }^{2}$ BSc, MB ChB, DCH, FCDerm, MMedSci; A Mosam, ${ }^{2}$ MB ChB, FCDerm, MMed, PhD \\ ${ }^{1}$ Dermatology Unit, Department of Paediatrics and Child Health, University of Ilorin, Kwara State, Nigeria \\ ${ }^{2}$ Department of Dermatology, Nelson R Mandela School of Medicine, University of KwaZulu-Natal, Durban, South Africa
}

Corresponding author: O S Katibi (oskatibi@gmail.com)

\begin{abstract}
Background. Skin conditions are common in children, and studying their spectrum in a tertiary dermatology clinic will assist in quantifying skin diseases associated with greatest burden.

Objective. To investigate the spectrum and characteristics of paediatric skin disorders referred to a tertiary dermatology clinic in Durban, KwaZulu-Natal (KZN) Province, South Africa.

Methods. A cross-sectional study of children attending the dermatology clinic at King Edward VIII Hospital, KZN, was carried out over 3 months. Relevant demographic information and clinical history pertaining to the skin conditions were recorded and diagnoses were made by specialist dermatologists. Data were analysed with EPI Info 2007 (USA).

Results. There were 419 children included in the study; 222 (53\%) were males and 197 (47\%) were females. A total of 64 diagnosed skin conditions were classified into 16 categories. The most prevalent conditions by category were dermatitis $(67.8 \%)$, infections (16.7\%) and pigmentary disorders (5.5\%). For the specific skin diseases, $60.1 \%$ were atopic dermatitis (AD), $7.2 \%$ were viral warts, $6 \%$ seborrhoeic dermatitis and $4.1 \%$ vitiligo. Dermatitis was significantly more common in males $(p<0.05)$. AD was the most common condition below 12 years of age, while the presence of viral warts was the most prevalent disorder among HIV-infected children. Approximately one-third (37.5\%) of the disorders referred by other medical practitioners were misdiagnosed.

Conclusions. AD constituted the highest burden both numerically and economically. Viral infections were a major contribution from HIV infection. The diverse spectrum and characteristics of skin diseases referred will assist in modifying the dermatology educational curriculum and bridge knowledge gaps among healthcare providers treating children.
\end{abstract}

S Afr J Child Health 2016;10(2):121-125. DOI:10.7196/SAJCH.2016v106i7.985

The spectrum of skin disorders seen in a population may reflect the level of hygiene, social development and health status of that community. ${ }^{[1]} \mathrm{A}$ higher number of infectious skin disorders have been found in developing countries compared with allergic disorders, which are more prominent in developed countries. ${ }^{[2,3]}$ Paediatric dermatological problems are common, with some conditions requiring specialist consultation. Often appropriate diagnosis and therapy are delayed because specialist dermatology services are only available in the larger cities and patients cannot access these readily. Conditions such as atopic dermatitis $(\mathrm{AD})$ may be associated with negative psychosocial impact and impaired quality of life for both the patients and affected family. ${ }^{[4]}$ Vitiligo and viral warts are also common diseases that lead to loss of self-esteem and psychological problems. ${ }^{[5]}$

At the time of the study, there was no recent documentation of the prevalence of skin disorders in children. The previous study of childhood-associated dermatoses was conducted 41 years ago by Findlay et al ${ }^{[6]}$ in Pretoria, with a focus mainly on white children. As such, it is imperative to study the current spectrum of skin diseases seen in children in a tertiary dermatology clinic, to assist in identifying diseases of greatest burden. This is paramount for public health intervention and future health planning. Therefore, this study aims to document the spectrum of paediatric skin diseases, investigating their relationship with age and gender, compare referring doctors' diagnoses with those of dermatologists, describe management modalities and estimate treatment costs.

\section{Methods}

This was a cross-sectional study involving all children (regardless of HIV status) aged $0-18$ years and attending the dermatology outpatient department of King Edward VIII Hospital, a regional hospital and the main teaching hospital for the Nelson R Mandela School of Medicine, University of KwaZulu-Natal (KZN), Durban. Children were recruited consecutively between May and August (autumn/winter) after ethical approval was granted by the Biomedical Research Ethical Committee (BREC) of the University of KZN in 2014 (BE026/14). A clear explanation of the study was given to each child's parent or caregiver, and signed informed consent was then obtained. Patients were reviewed by specialist dermatologists, and diagnoses were clinical and corroborated by appropriate investigations where necessary. Data collection sheets recorded relevant clinical history, demographics and therapeutic management of the skin disorder. Data were entered into a Microsoft (USA) Excel spreadsheet 2007 and analysed with EPI Info 2007 (USA). Direct costs of major skin conditions were calculated based on average cost of consultation (ZAR40) and the commercial cost of the standard medications for each condition. This was calculated in South African Rands (ZAR) and converted to US dollars (USD) using the average prevailing exchange rate at the time of the study (1 USD to 10 ZAR).

\section{Results}

\section{Characteristics of study participants}

A total of 419 children were studied. There were 367 (87.6\%) black children, 40 (9.5\%) Indians, $11(2.6 \%)$ mixed race and 1 white child $(0.2 \%)$. There were slightly more male patients $222(53 \%)$ than female patients 197 (47\%). Ages ranged from 1 week to 18 years with a mean (standard deviation) age of 56.04 (49.14) months. Infants ( $<2$ years) accounted for $30.3 \%$, preschool ( 2 - 5 years) $33.7 \%$, school age (6 11 years) $28.2 \%$ and adolescents (12 - 18 years) $7.8 \%$. 


\section{Spectrum of skin disorders found}

A total of 64 skin diseases were diagnosed and classified into 16 categories. The most prevalent disorders by category were dermatitis $(67.8 \%)$, infections $(16.7 \%)$, pigmentary $(5.5 \%)$, papulosquamous $(4.5 \%)$, appendageal (3.1\%), vascular (2.4\%) and genodermatoses (1.2\%) (Table 1 and Fig. 1). Multiple diagnoses were made in $9.8 \%$ of the patients.

\section{Skin disorders in relation to gender and age groups}

A higher preponderance of males with dermatitis was seen (odds ratio 1.57, 95\% confidence interval $1.13-2.19 ; p=0.007$ ). Table 1 shows the gender distribution of skin lesions. $\mathrm{AD}$ was the most common disorder below 12 years of age while viral warts and acne vulgaris were most common above this age. Seborrhoeic dermatitis, impetigo, nappy dermatitis and infantile haemangioma were most common in infancy (Table 2).

\section{Comparison of diagnoses of referring doctors to those of dermatologists}

Among children referred with a skin diagnosis, 65 (62.5\%) had a correct diagnosis while 39 (37.5\%) had an incorrect diagnosis. Three cases each of chronic bullous disease of childhood, pityriasis rosea, verruca plana and scabies were newly referred and they were all misdiagnosed by referring doctors. AD was appropriately diagnosed in $90.2 \%$ of cases.

\section{Dermatoses in HIV-infected children}

Infections were seen in 23 (82.1\%) of the $28 \mathrm{HIV}$-infected children. Viral warts $(60.7 \%)$ were the most common conditions and accounted for $56.7 \%$ of the warts seen in the whole study population. $\mathrm{AD}(28.6 \%)$ was the most common non-infectious disease (Table 3).

\section{Management modalities and treatment costs}

Skin biopsy was carried out in $16(3.8 \%)$ patients while 35 (8.4\%) had blood assays done. Management modalities included topical therapy $(92.8 \%)$, systemic therapy $(14.3 \%)$, wet wrap therapy $(2.1 \%)$, cryotherapy (1.9\%) and counselling alone (1.9\%). Some of these treatment modalities were used in combination. The estimated costs of consultation of the common diseases based on costs of prescription medications are highlighted in Table 4.

\section{Discussion}

The spectrum of paediatric skin diseases in a tertiary dermatology centre gives an insight into the diseases that are associated with diagnostic difficulty, chronicity and/or severity and greater financial implication.

\section{Spectrum of skin disorders}

A variety of skin disorders were seen, including inflammatory, infections and pigmentary disorders. Multiple diagnoses were made in $9.8 \%$ of the studied population and this is similar to the $11 \%$ reported by Hon et al. ${ }^{[7]}$ in China. Some of the co-existent conditions in this study, viz. alopecia areata and impetigo were totally unrelated, while other conditions like $\mathrm{AD}$ and molluscum contagiosum were closely linked. This should prompt medical practitioners to look out for other lesions on the skin apart from the presenting skin complaint. The prevalent disease categories were dermatitis (67.8\%), infections (16.7\%) and pigmentary problems (5.5\%). This pattern was also reported by Shibeshi ${ }^{[8]}$ in Ethiopia, where allergic skin diseases accounted for $55.1 \%$, followed by the infections $(32.8 \%)$ and photodermatoses (8\%). Hon et al. ${ }^{[7]}$ in China also found allergic skin diseases and eczema to be the most common. However, infections were the highest in studies from Egypt and Nigeria, where poor hygiene, low socioeconomic levels and poor health awareness are prevalent. ${ }^{[1,2]}$

\section{Dermatitis/eczema}

AD $(60.1 \%)$ occurred in every second child seen in the clinic. This prevalence rate, which is one of the highest reported in literature, is three times more than the $18.7 \%$ documented 40 years ago in Pretoria. ${ }^{[6]}$ This high rate may be attributed to higher standards of

Table 1. Prevalence of cutaneous disorders and gender distribution

\begin{tabular}{|c|c|c|c|}
\hline Cutaneous lesion & Male & Female & $n(\%)$ \\
\hline Dermatitis & 158 & 126 & $284(67.8)$ \\
\hline $\mathrm{AD}$ & 140 & 112 & $252(60.1)$ \\
\hline Seborrhoeic dermatitis & 16 & 9 & $25(6.0)$ \\
\hline Nappy dermatitis & 2 & 2 & $4(1.0)$ \\
\hline Papular urticaria & 1 & 3 & $4(1.0)$ \\
\hline Contact eczema & 0 & 2 & $2(0.5)$ \\
\hline Lip-licking dermatitis & 1 & 0 & $1(0.2)$ \\
\hline Perioral dermatitis & 0 & 1 & $1(0.2)$ \\
\hline Foot dermatitis & 1 & 0 & $1(0.2)$ \\
\hline Erythroderma & 0 & 1 & $1(0.2)$ \\
\hline Infections & 38 & 32 & $70(16.7)$ \\
\hline Viral & 23 & 23 & $46(11)$ \\
\hline Viral warts & 14 & 16 & $30(7.2)$ \\
\hline Molluscum contagiosum & 9 & 7 & $16(3.8)$ \\
\hline Chicken pox & 1 & 1 & $2(0.5)$ \\
\hline Fungal & 9 & 5 & $14(3.3)$ \\
\hline Dermatophytosis & 8 & 4 & $12(2.9)$ \\
\hline Oral candidiasis & 1 & 0 & $1(0.2)$ \\
\hline Nappy candidiasis & 0 & 1 & $1(0.2)$ \\
\hline Pityriasis vesicolor & 1 & 0 & $1(0.2)$ \\
\hline Bacterial & 4 & 6 & $10(2.4)$ \\
\hline Impetigo & 2 & 5 & $7(1.7)$ \\
\hline Folliculitis & 2 & 1 & $3(0.7)$ \\
\hline Furuncles & 0 & 1 & $1(0.2)$ \\
\hline Parasitic & 3 & 0 & $3(0.7)$ \\
\hline Scabies & 3 & 0 & $3(0.7)$ \\
\hline Mycobacterial & 1 & 0 & $1(0.2)$ \\
\hline Lupus vulgaris & 1 & 0 & $1(0.2)$ \\
\hline Pigmentary & 12 & 11 & $23(5.5)$ \\
\hline Vitiligo & 10 & 7 & $17(4.1)$ \\
\hline Albinism & 1 & 4 & $5(1.2)$ \\
\hline Mongolian spots & 1 & 0 & $1(0.2)$ \\
\hline Papulosquamous & 7 & 12 & $19(4.5)$ \\
\hline Psoriasis & 1 & 2 & $3(0.7)$ \\
\hline Pityriasis rosea & 2 & 2 & $4(1)$ \\
\hline Pityriasis alba & 0 & 2 & $2(0.5)$ \\
\hline Pityriasis lichenoides chronica & 1 & 2 & $3(0.7)$ \\
\hline Lichen planus & 1 & 1 & $2(0.5)$ \\
\hline Lichen nitidus & 0 & 1 & $1(0.2)$ \\
\hline Lichen spinulosus & 0 & 1 & $1(0.2)$ \\
\hline Gianotti crosti syndrome & 1 & 1 & $2(0.5)$ \\
\hline \multirow[t]{2}{*}{ LP/LE overlap } & 1 & 0 & $1(0.2)$ \\
\hline & & & Continued \\
\hline
\end{tabular}


living in the new cohort, industrialisation, migration from rural to urban and suburban areas, and a westernised lifestyle compared

Table 1. (continued) Prevalence of cutaneous disorders and gender distribution

\begin{tabular}{|c|c|c|c|}
\hline Appendages & 7 & 6 & $13(3.1)$ \\
\hline Acne vulgaris & 5 & 3 & $8(1.9)$ \\
\hline Alopecia areata & 2 & 1 & $3(0.7)$ \\
\hline Onycholysis & 0 & 1 & $1(0.2)$ \\
\hline Miliaria crystalline & 0 & 1 & $1(0.2)$ \\
\hline Vascular & 3 & 7 & $10(2.4)$ \\
\hline Infantile haemangioma & 2 & 4 & $6(1.4)$ \\
\hline Phakomatosis pigmentovascularis & 0 & 1 & $1(0.2)$ \\
\hline Nevus flammeus & 1 & 1 & $2(0.5)$ \\
\hline Klippel trenaunay & 0 & 1 & $1(0.2)$ \\
\hline Genodermatoses & 4 & 1 & $5(1.2)$ \\
\hline Giant congenital melanocytic naevus & 1 & 0 & $1(0.2)$ \\
\hline Epidermal naevus & 0 & 1 & $1(0.2)$ \\
\hline Naevus sebaceous & 1 & 0 & $1(0.2)$ \\
\hline ILVEN & 1 & 0 & $1(0.2)$ \\
\hline Xeroderma pigmentosum & 1 & 0 & $1(0.2)$ \\
\hline Disorders of cornification & 1 & 3 & $4(1.0)$ \\
\hline Ichthyosis & 1 & 3 & $4(1.0)$ \\
\hline Sclerosing disorders & 0 & 4 & $4(1.0)$ \\
\hline Morphea & 0 & 4 & $4(1.0)$ \\
\hline Vesicobullous & 2 & 2 & $4(1.0)$ \\
\hline Acropustulosis of infancy & 0 & 1 & $1(0.2)$ \\
\hline CBDC & 2 & 1 & $3(0.7)$ \\
\hline Urticaria & 3 & 1 & $4(1.0)$ \\
\hline Angioneurotic oedema & 1 & 0 & $1(0.2)$ \\
\hline Chronic urticaria & 2 & 1 & $3(0.7)$ \\
\hline Dermis \& subcutaneous nodules & 1 & 2 & $3(0.7)$ \\
\hline Mastocytosis & 1 & 1 & $2(0.5)$ \\
\hline Erythema nodosum & 0 & 1 & $1(0.2)$ \\
\hline Connective tissue diagnosis & 0 & 2 & $2(0.5)$ \\
\hline Discoid lupus erythematosus & 0 & 1 & $1(0.2)$ \\
\hline Mixed connective tissue diagnosis & 0 & 1 & $1(0.2)$ \\
\hline Malignancy & 1 & 1 & $2(0.5)$ \\
\hline Actinic keratosis & 0 & 1 & $1(0.2)$ \\
\hline Squamous cell cancer & 1 & 0 & $1(0.2)$ \\
\hline Drug reaction & 1 & 0 & $1(0.2)$ \\
\hline Fixed drug reaction & 1 & 0 & $1(0.2)$ \\
\hline Miscellaneous & 4 & 0 & $4(1.0)$ \\
\hline Primary immune deficiency & 1 & 0 & $1(0.2)$ \\
\hline Leukaemoid reaction & 1 & 0 & $1(0.2)$ \\
\hline Skin necrosis (IV fluid) & 1 & 0 & $1(0.2)$ \\
\hline Arthropod bite & 1 & 0 & $1(0.2)$ \\
\hline
\end{tabular}

LP/LE = lichen planus/lupus erythematosus; ILVEN = inflammatory linear verrucous epidermal naevus; $\mathrm{CBDC}=$ chronic bullous dermatosis of childhood. with other parts of sub-Saharan Africa. Further research is needed to determine environmental or genetic predispositions to this disorder. Since the diagnostic accuracy for physicians referring $\mathrm{AD}$ patients was good, the treatment of this disorder may have been a challenge to first-line healthcare providers, hence the high numbers referred to the clinic for possible second-line treatment. Further attention therefore needs to be given to the appropriate management of these children at the primary care level. This will improve outcome and decrease referral to tertiary centres.

Seborrhoeic dermatitis (6\%) has been strongly associated with HIV infection. Despite the endemic nature and high prevalence of HIV in KZN, only one of the 25 children with seborrhoeic dermatitis was HIV-infected. Human T-cell lymphotropic virus 1 (HTLV-1) infective dermatitis presents in a similar pattern to seborrhoeic dermatitis but none of the patients seen had this disorder. The reduction in prevalence of seborrhoeic dermatitis after infancy is presumably due to reduced stimulation of maternal androgens transferred to the infant in utero. ${ }^{[9]}$ In this cohort, the success of the widespread roll-out of antiretroviral medications to HIV-infected pregnant women has most likely caused the reduction in HIV prevalence in children.

\section{Infections}

Viral infections (11\%) were the most prevalent infections. In studies where $\mathrm{AD}$ is most prevalent, viral infections tend to be the most commonly associated infections. ${ }^{[3,7,10]}$ These are reports from tertiary dermatology centres and may indicate that among the infections, viral dermatoses pose the greatest management challenge for primary care doctors. Orogenital warts accounted for 20 of the 30 cases of warts encountered. HIV infection may be responsible for this because over half of the viral warts in this study were found in HIV-infected children. High rates of sexual abuse could account for the increased frequency of these type of warts. ${ }^{[11]}$ This trend should alert managing doctors to take an in-depth history into child abuse and notify the relevant health authorities. Heck's disease, a variant of oral warts (Fig. 2) seen in some patients, has been found to be more common in some regions of the world, including South Africa. ${ }^{[12]}$ About $40 \%$ of the patients with molluscum contangiosum were HIV-infected, and this could also be a contribution of HIV to paediatric dermatoses. Tinea capitis was the predominant type of superficial dermatophytosis seen $(2.9 \%)$, with a male preponderance. Its occurrence in a specialty clinic may be due to inadequate treatment, as oral antifungal medication is indicated for at least 6 weeks. The prevalence rate of impetigo (1.7\%) was relatively low compared with the findings in Egypt (19.1\%), where overcrowding, lack of hygiene and antibiotic resistance from indiscriminate use have been implicated. ${ }^{[1]}$

\section{Pigmentary}

There were more male patients with vitiligo (4.1\%), with ages ranging between 2 and 11 years. Management included potent topical steroids, vitamin $\mathrm{D}$ analogues and topical calcineurin inhibitors. Albinism was more common in females $(80 \%)$, with one patient presenting with actinic keratosis at the age of 6 years. Education about the dangers of ultraviolet exposure in this group is paramount.

\section{Others}

Acne vulgaris was seen only in adolescents and supports the role of higher production of sebum and androgens in the pathogenesis of the disorder in this age group. Most of the papulosquamous dermatoses were seen in children 6 years and above. A variety of vascular problems $(2.4 \%)$ and genodermatoses $(1.2 \%)$ were seen. Infantile haemangiomas involved areas like the lips, scalp, labia and cheek. Xeroderma pigmentosum was seen in an 11-year-old black boy who developed squamous cell carcinoma (SCC) on the scalp (Fig. 3). This rare autosomal recessive condition is characterised by severe photosensitivity and defective DNA repair. Solar keratosis and SCC 


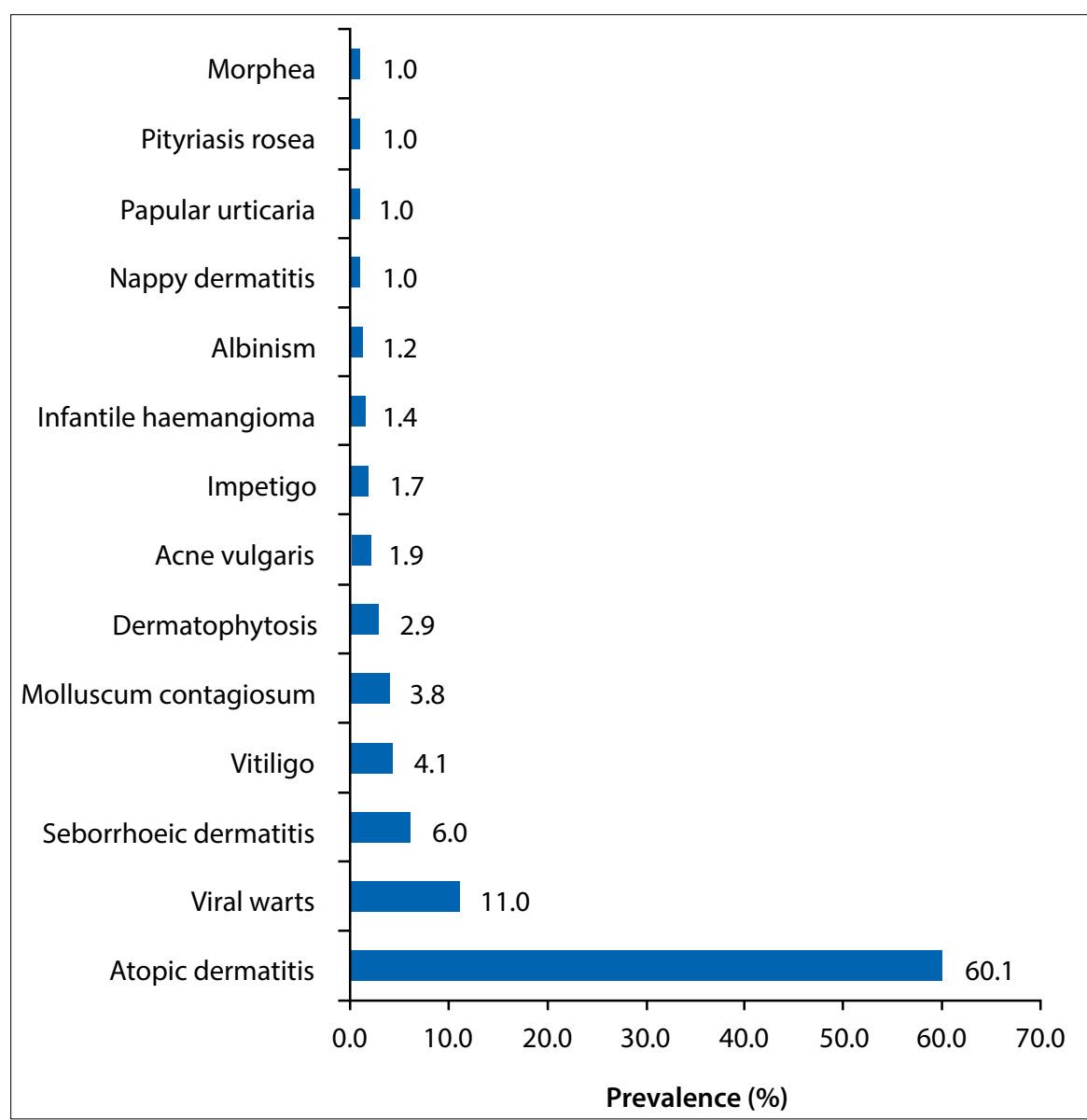

Fig. 1. Most prevalent skin disorders seen among the study population.

Table 2. Distribution of most common skin diseases by age group

\begin{tabular}{llll}
\hline $\begin{array}{l}\mathbf{0}-<2 \text { years } \\
(\boldsymbol{n}=\mathbf{1 2 7})\end{array}$ & $\begin{array}{l}\text { 2 - 5 years } \\
(\boldsymbol{n}=\mathbf{1 4 1})\end{array}$ & $\begin{array}{l}\mathbf{6}-\mathbf{1 1} \text { years } \\
(\boldsymbol{n}=\mathbf{1 1 8})\end{array}$ & $\begin{array}{l}\mathbf{1 2}-\mathbf{1 8} \text { years } \\
(\boldsymbol{n}=\mathbf{3 3})\end{array}$ \\
\hline $\mathrm{AD}(63.8 \%)$ & $\mathrm{AD}(68.8 \%)$ & $\mathrm{AD}(59.3 \%)$ & $\begin{array}{l}\text { Acne vulgaris } \\
(24.2 \%)\end{array}$ \\
$\begin{array}{l}\text { Seborrhoeic dermatitis } \\
(11.8 \%)\end{array}$ & Viral warts (7.8\%) & Viral warts $(9.3 \%)$ & $\begin{array}{l}\text { Viral warts } \\
(24.2 \%)\end{array}$ \\
$\begin{array}{l}\text { Infantile haemangioma } \\
(3.1 \%)\end{array}$ & Vitiligo (5.7\%) & $\begin{array}{l}\text { Molluscum } \\
\text { contagiosum }(6.8 \%)\end{array}$ & $\mathrm{AD} \mathrm{(12.1 \% )}$ \\
$\begin{array}{l}\text { Impetigo (3.1\%) } \\
\text { Nappy dermatitis (3.1\%) }\end{array}$ & $\begin{array}{l}\text { Dermatophytosis (5.0\%) } \\
\text { Seborrhoeic dermatitis (5.0\%) }\end{array}$ & Vitiligo (5.1\%) & Vitiligo (7\%) \\
& & &
\end{tabular}

are complications that arise early in life and are characterised by a rapid and devastating course.

\section{Relationship between age, sex and skin disorders}

A higher male preponderance was found in children under the age of 5 years compared with older children. This was noted by Findlay et al. ${ }^{[6]}$ and attributed to increasing concern and awareness of the skin among females as they approach puberty. Marrone et al. ${ }^{[13]}$ noted more fungal and parasitic infections in males and this is corroborated in this study. The more adventurous nature of boys leading to more play outside in the sand may account for this picture. The trend of $\mathrm{AD}$ peaking in the preschool age and reducing significantly in adolescence is consistent with previous observations that this condition improves with age.

\section{Referring to the dermatologist's diagnosis}

Skin diseases are usually referred to the dermatologist because of treatment difficulty or diagnostic dilemma. Diseases such as AD that were well recognised in this study fall into

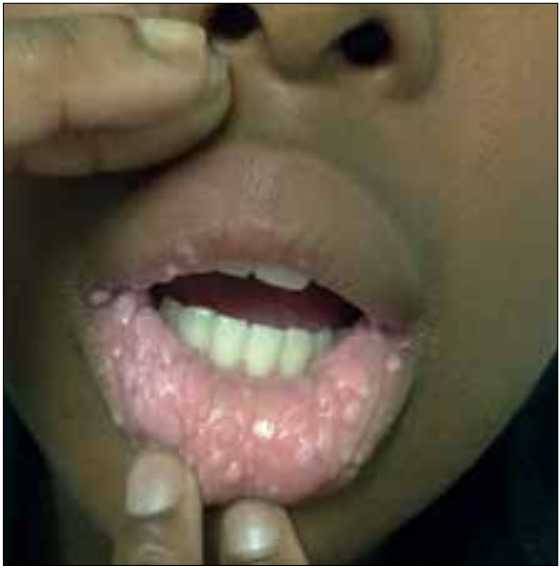

Fig. 2. Heck's disease, a variant of oral warts.

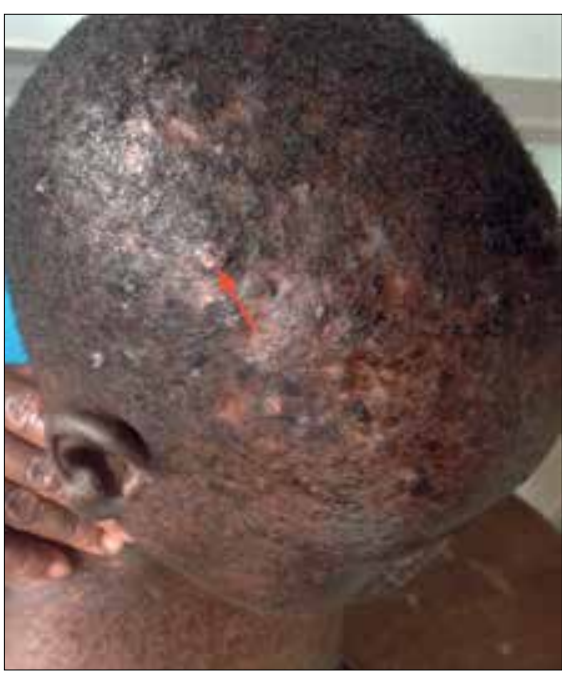

Fig. 3. Xeroderma pigmentosum in an 11-year-old child who developed SCC on the scalp.

the former, while others like verruca plana and scabies which were misdiagnosed fall into the latter category. This information will be useful in educating general practitioners and paediatricians.

\section{Management modalities of skin diseases and estimated costs}

Documentations in referral dermatology clinics have shown skin biopsy rates between 0.8 and $12 \%$, which is consistent with our finding of $3.8 \%{ }^{[3,7]}$ Biopsies were performed for less-common diseases such as actinic keratosis, SCC, chronic bullous disease of childhood, psoriasis and connective tissue diseases. Afsar et al.. ${ }^{[14]}$ in Turkey, reported Henoch-Schönlein purpura and various papulosquamous diseases as the most common reason for biopsy in children. Skinprick test was the most common investigation in Switzerland, and this is most likely due to incorporation of allergology with paediatric dermatology. ${ }^{[3]}$ About $80 \%$ of patients in this study had topical treatments in the form of steroids, antibiotics, calcineurin inhibitors and keratolytics. Topical steroids were part of 
Table 3. Comparison of skin disorders between HIV-positive and other children in the population

\begin{tabular}{llll}
\hline Skin disorders & $\begin{array}{l}\text { HIV-positive, } \\
\boldsymbol{n}(\%)(\boldsymbol{n}=\mathbf{2 8})\end{array}$ & $\begin{array}{l}\text { Other, } \boldsymbol{n}(\%) \\
(\boldsymbol{n}=391)\end{array}$ & $\begin{array}{l}\text { Total, } \boldsymbol{n}(\%) \\
(\boldsymbol{N}=419)\end{array}$ \\
\hline Infections & $23(82.1)$ & $47(12.0)$ & $70(16.7)$ \\
Viral warts & $17(60.7)$ & $13(3.3)$ & $30(11.0)$ \\
$\quad$ Anogenital warts & $4(14.3)$ & $7(1.8)$ & $11(2.6)$ \\
$\quad$ Oral papillomas & $4(14.3)$ & $5(1.3)$ & $9(2.1)$ \\
$\quad$ Plane warts & $7(25.0)$ & $2(0.5)$ & $9(2.1)$ \\
$\quad$ Verruca vulgaris & $3(10.7)$ & $0(0.0)$ & $3(0.7)$ \\
Molluscum contagiosum & $7(25.0)$ & $9(2.3)$ & $16(3.8)$ \\
Dermatophytosis & $4(14.3)$ & $8(2.0)$ & $12(2.9)$ \\
$\quad$ Tinea capitis & $3(10.7)$ & $7(1.8)$ & $10(2.4)$ \\
$\quad$ Tinea cruris & $1(3.6)$ & $0(0.0)$ & $1(0.2)$ \\
Dermatitis & $8(28.6)$ & $276(70.6)$ & $284(67.8)$ \\
AD & $6(21.4)$ & $246(62.9)$ & $252(60.1)$ \\
Seborrhoeic dermatitis & $1(3.6)$ & $24(6.1)$ & $25(6.0)$ \\
Perioral dermatitis & $1(3.6)$ & $0(0.0)$ & $1(0.2)$ \\
Pityriasis alba & $1(3.6)$ & $1(0.3)$ & $2(0.5)$ \\
Papulosquamous & $1(3.6)$ & $18(4.6)$ & $19(4.5)$ \\
Pityriasis lichenoides chronica & $1(3.6)$ & $2(0.5)$ & $3(0.7)$ \\
Appendages & $1(3.6)$ & $12(3.1)$ & $13(3.1)$ \\
Acne vulgaris & $1(3.6)$ & $7(1.8)$ & $8(1.9)$ \\
& & &
\end{tabular}

Table 4. Direct cost of consultation and medication of skin diseases per visit

\begin{tabular}{lll}
\hline Skin disorder & Cost per patient (USD) & Total cost for all patients (USD) \\
\hline AD & 86.97 & 21916.4 \\
Viral warts & 46.81 & 2340.5 \\
Seborrhoeic dermatitis & 86.97 & 2174.3 \\
Vitiligo & 96.33 & 1637.6 \\
Molluscum contagiosum & 46.81 & 749.0 \\
Dermatophytoses & 54.28 & 651.4 \\
Acne vulgaris & 142.93 & 1143.4
\end{tabular}

management in $47 \%$ of the patients in China, while in Switzerland, $66 \%$ of the patients had local therapy. ${ }^{[3,7]}$ Cryotherapy was used for oral papillomas, some cutaneous warts and molluscum contagiosum. There are few reports in the literature that document the impact of costs on the management of paediatric skin diseases. In a study sponsored by the American Academy of Dermatology, ${ }^{[15]}$ the direct cost of treatment in the general population was highest with skin ulcers, acne vulgaris, cutaneous fungal infections and AD. This is reflected in this study, as $\mathrm{AD}$ is the most common of these diseases in the paediatric age group and has the highest economic burden that is about 20 times that of acne vulgaris. Most of these costs are largely owing to prescription medications.

\section{Conclusion}

The spectrum of paediatric skin diseases in KZN is diverse. AD constituted a high burden both numerically and financially. Viral infections were a major contribution from HIV infection. Diseases such as scabies, chronic bullous dermatosis of childhood and verruca planar that were misdiagnosed by referring primary care doctors will help inform modification of dermatology educational curriculum.

The knowledge of spectrum of diseases will assist in prioritising drugs that can be included in the 'essential drug lists' of clinics and hospital in the province and help improve medical drug supplies. Age- and gender-related dermatoses as well as the financial implications of common paediatric skin diseases would be useful for future health planning in order to reduce disease burden.

Acknowledgements. We are extremely grateful to the staff of the Department of Dermatology, University of KwaZulu-Natal, for the support given in publishing this manuscript.

\section{References}

1. El-Khateeb EA. The spectrum of paediatric dermatoses in a university hospital in Cairo, Egypt. J Eur Acad Dermatol Venereol 2011;25(6):666672. DOI:10.1111/j.1468-3083.2010.03846.x

2. Ogunbiyi AO, Daramola OO, Alese OO Prevalence of skin diseases in Ibadan, Nigeria. Int J Dermatol 2004;43(1):31-36. DOI:10.1111/j.13654632.2004.01967.x

3. Wenk C, Itin PH. Epidemiology of pediatric dermatology and allergology in the region of Aargau, Switzerland. Pediatr Dermatol 2003;20(6):482-487. DOI:10.1111/j.1525-1470. 2003.20605.x

4. Carroll CL, Balkrishnan R, Feldman SR, et al. The burden of atopic dermatitis: Impact on the patient, family, and society. Pediatr Dermatol 2005;22(3):192199. DOI:10.1111/j.1525-1470.2005.22303.x

5. Hill-Beuf A, Porter JD. Children coping with impaired appearance: Social and psychologic influences. Gen Hosp Psychiatry 1984;6(4):294 301. DOI:10.1016/0163-8343(84)90024-0

6. Findlay GH, Vismer HF, Sophianos T. The spectrum of paediatric dermatology. Analysis of 10000 cases. Br J Dermatol 1974;91(4):379-387. DOI:10.1111/j.1365-2133.1974.tb13075.x

7. Hon KL, Leung TF, Wong Y, et al. Skin diseases in Chinese children at a pediatric dermatology center. Pediatr Dermatol 2004;21(2):109-112. DOI:10.1111/j.0736-8046.2004.21203.x

8. Shibeshi D. Pattern of skin disease at the EthioSwedish pediatric hospital, Addis Ababa, Ethiopia. Pediatr Dermatol 2000;17(5):357-359. DOI:10.1046/j.1525-1470.2000.017005357.x

9. Berth Jones J. Rook's eczema, lichenification, prurigo and erythroderma. In: Burns DA, Breathnach SM, Cox NH, Griffiths CEM, eds. Rook's Textbook of Dermatology. 8th ed. West Sussex: Blackwell Publishing Ltd, 2010:23-29. DOI:10.1002/9781444317633.ch23

10. Nanda A, Al-Hasawi F, Alsaleh QA. A prospective survey of pediatric dermatology clinic patients in Kuwait: An analysis of 10000 cases. Pediatr Dermatol 1999;16(1):6-11. DOI: 10.1046/j.15251470.1999.99002.x

11. Violence against Children in South Africa Pretoria: Department of Social Development/ Department of Women, Children and People with Disabilities/UNICEF, 2012. http://www. cjcp.org.za/uploads/2/7/8/4/27845461/vac_final_ summary low res.pdf (accessed 2 May 2015).

12. van Wyk W, Harris A. Focal epithelial hyperplasia: A survey of two isolated communities in the Cape Province of South Africa. Community Dent Oral Epidemiol 1987;15(3):161-63. DOI:10.1111/j.1600-0528.1987.tb00506.x

13. Marrone R, Vignally $P$, Rosso A, et al. Epidemiology of skin disorders in Ethiopian children and adolescents: An analysis of records from the Italian Dermatological Centre, Mekelle, Tigray, Ethiopia, 2005 to 2009. Pediatr Dermatol 2012;29:442-447. DOI:10.1111/j.1525-1470.2011.01698.x

14. Afsar FS, Aktas S, Diniz G, et al. The role of biopsy in pediatric dermatopathology. Turkdurm 2011;45(3):137-139. DOI:10.4274/ turkderm.87894

15. Bickers DR, Lim HW, Margolis D, et al. The burden of skin diseases: 2004: A joint project of the American Academy of Dermatology Association and the Society for Investigative Dermatology. J Am Acad Dermatol 2006;55(3):490-500 DOI:10.1016/j.jaad.2006.05.048 